\title{
Expression of p53 Breast Cancer in Kurdish Women in the West of Iran: a Reverse Correlation with Lymph Node Metastasis
}

\author{
Mehrdad Payandeh ${ }^{1}$, Masoud Sadeghi $^{2,3 *}$, Edris Sadeghi $^{2,3}$, Seyed-Hamid Madani ${ }^{4}$
}

\begin{abstract}
Background: In breast cancer (BC), it has been suggested that nuclear overexpression of p53 protein might be an indicator of poor prognosis. The aim of the current study was to evaluate the expression of p53 $\mathrm{BC}$ in Kurdish women from the West of Iran and its correlation with other clinicopathology figures. Materials and Methods: In the present retrospective study, 231 patients were investigated for estrogen receptor (ER) and progesterone receptor (PR) positivity, defined as $\geq 10 \%$ positive tumor cells with nuclear staining. A binary logistic regression model was selected using Akaike Information Criteria (AIC) in stepwise selection for determination of important factors. Results: ER, PR, the human epidermal growth factor receptor 2 (HER2) and p53 were positive in $58.4 \%, 55.4 \%, 59.7 \%$ and $45 \%$ of cases, respectively. Ki67 index was divided into two groups: $54.5 \%$ had Ki67 $<20 \%$ and $45.5 \%$ had Ki67 $\geq 20 \%$. Of 214 patients, 137(64\%) had lymph node metastasis and of 186 patients, 122(65.6\%) had vascular invasion. Binary logistic regression analysis showed that there was inverse significant correlation between lymph node metastasis $(P=0.008$, OR 0.120 and $95 \% C I$ 0.025-0.574), ER status $(P=0.006$, OR 0.080, 95\% CI 0.014-0.477) and a direct correlation between HER2 (P=005, OR 3.047, 95\% CI 1.407-6.599) with the expression of p53. Conclusions: As in a number of studies, expression of p53 had a inverse correlation with lymph node metastasis and ER status and also a direct correlation with HER2 status. Also, p53-positivity is more likely in triple negative $\mathrm{BC}$ compared to other subtypes.
\end{abstract}

Keywords: Breast cancer - Kurdish ethnicity - P53 - receptor expression - lymph node metastasis

Asian Pac J Cancer Prev, 17 (3), 1261-1264

\section{Introduction}

Breast cancer $(\mathrm{BC})$ is the most frequent malignancy among women worldwide and is a heterogeneous disease with distinct pathological and histological features, and can be classified into several subtypes based on the expression of 3 receptors: estrogen receptor (ER), progesterone receptor (PR), and the human epidermal growth factor receptor 2 (HER2) (Payandeh et al., 2015a) that can be a leading cause of death through middle-aged women and this cancer accounts about one fifth of all female malignancy. BC is the leading cause of death in high income countries and second leading cause in low and middle income countries (Payandeh et al., 2015b). Many genetic traits common to aggressive breast carcinoma have been identified; yet little is known about the interrelationships of such traits during tumor development, especially in women prone to aggressive cancer (Howard et al., 2004).

Conventional clinicopathological parameters such as age of the patient, the degree of histological differentiation, nuclear grade, the size of the primary tumor, the status of axillary lymph nodes and in the recent era the immunohistochemistry (IHC), determining hormone status, proliferative index, severity or amplification the HER2 gene and p53 gene mutations have been shown as important prognostic parameters regarding the course and outcome of the disease (Lacroix et al., 2006; De Azambuja et al., 2007).

The mutation of the p53 gene is a common phenomenon in numerous human tumors, leading to the accumulation of nonfunctioning $\mathrm{p} 53$ protein in the cell nucleus, which can be detected by IHC (Temmimet et al., 2001). In BC, it has been suggested that the overexpression of $\mathrm{p} 53$ protein in the nucleus is an indicator of poor prognosis (Sirvent et al., 1995; Temmim et al., 2001) and most investigators have reported poorer overall and disease-free survival (Pharoah et al., 1999). The many roles of p53 as a tumor suppressor include the ability to induce cell cycle arrest, DNA repair, senescence, and apoptosis, to name only a few (Aylon and Oren, 2011).

The aim of the current study was to evaluate the expression of $\mathrm{p} 53$ in women with $\mathrm{BC}$ in and its correlation with other clinicopathology figures in Kurdish patients with $\mathrm{BC}$ in the West of Iran, and to compare these to other studies. 


\section{Materials and Methods}

In a retrospective study, 231 patients with $\mathrm{BC}$ entered to our study. They received chemotherapy, radiotherapy or hormone therapy. A lot of patients underwent primary surgery. A sufficient sample size was selected from any patient and the slides were stained by hematoxylin and eosin (H \& E) method. Then 4-micron sections were prepared for staining with $\mathrm{H} \& \mathrm{E}$ and also for IHC (Ki67, ER, PR, p53 and HER2) staining. ER and PR positivity was defined as $\geq 10 \%$ positive tumor cells with nuclear staining. HER2-positive was defined as either HER2 gene amplification by fluorescent in situ hybridization (FISH) or scored as 3+ by IHC. In case of HER2 (2+), FISH was performed to determine HER2 positivity. Age, tumor size, lymph node involvement, histological grade, nuclear grade, vascular invasion, p53 and Ki67 index were other factors that determined in a lot of patients. P53 nuclear stains were scored as positive for strong, uniform staining of the tumor nuclei, as indeterminate for weak or focal nuclear staining, and as negative for no staining. In this study, hormone receptor (HR)-positive and HER2-negative tumors were classified as luminal A type; HR-positive and HER2-positive tumors (HER2 IHC: $3+$ or $2+$ that amplified by FISH) as luminal B type; HR-negative and HER2-positive tumors as HER2 disease; and HR-negative and HER2-negative tumors as triple negative (TN) type (Aeinfar et al., 2015). The correlation between the variables was done by IBM SPSS statistics 19. Chi-square test was used to analyze the significance of correlation between the expression of Ki67 and other parameters and $\mathrm{P}<0.05$ was considered significant. Also, a binary logistic regression model was selected using Akaike Information Criteria (AIC) in stepwise selection for determination of more important factors.

\section{Results}

The mean age for the patients at diagnosis was $47.6 \pm 9$ years (range, 24-82 years) with $100 \%$ female (Table 1). The patients were divided to two age group: 105 patients $(64.9 \%)$ had age $\leq 50$ years and $81(35.1 \%)$ had age $>50$ years. Of 231 patients, 221 patients were checked for tumor size that 31 patients $(14 \%)$ had size $<2 \mathrm{~cm}$ and $190(86 \%)$ had size $\geq 2 \mathrm{~cm}$. Of 210 patients, $43(20.5 \%)$, $123(58.6 \%)$ and $44(21 \%)$ had histological grade I, II and III and also of 134 patients, 32(26.1\%), 75(56\%) and 24 (17.9\%) had nuclear grade I, II and III, respectively. Of

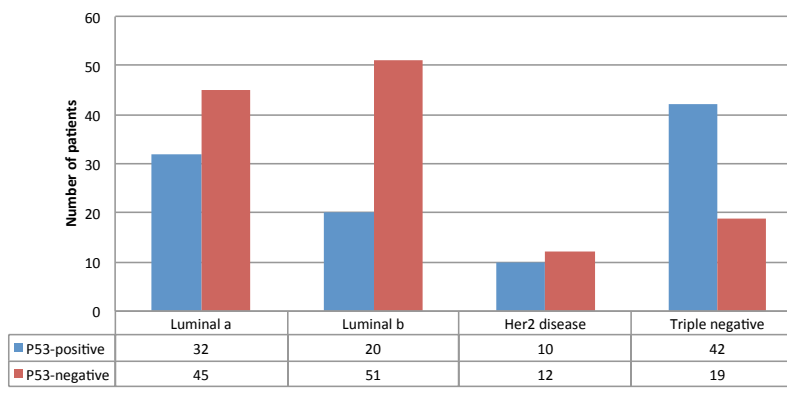

Figure 1. The Correlation between Subtypes of Breast Cancer with the Expression of p53
214 patients, $137(64 \%)$ had lymph node metastasis and of 186 patients, $122(65.6 \%)$ had vascular invasion. Of all patients, ER, PR, HER2 and p53 were positive for $135(58.4 \%), 128(55.4 \%), 138(59.7 \%)$ and 104(45\%), respectively. Ki67 index was divided to two groups: 126 (54.5\%) had Ki67 <20\% and 105(45.5\%) had Ki67 $\geq 20 \%$.

The correlation between the expression of p53 with other factors in BC patients has been shown in Table 2. There was significant correlation between the expression of P53 with age group, histological grade, nuclear grade,

Table 1. The baseline characteristics of patients with breast cancer $(\mathbf{n}=\mathbf{2 3 1})$

\begin{tabular}{|c|c|c|c|}
\hline Variables & $\mathrm{n}(\%)$ & Mean \pm SD & Range \\
\hline$\overline{\text { Age group(year) }}$ & & $47.6 \pm 9.0$ & $24-82$ \\
\hline$\leq 50$ & $150(64.9)$ & & \\
\hline$>50$ & $81(35.1)$ & & \\
\hline \multicolumn{4}{|l|}{ Sex } \\
\hline Male & $0(0)$ & & \\
\hline Female & $100(100)$ & & \\
\hline \multicolumn{4}{|l|}{ Tumor Size (cm) } \\
\hline$<2$ & $31(14)$ & & \\
\hline$\geq 2$ & $190(86)$ & & \\
\hline NA & 10 & & \\
\hline \multicolumn{4}{|l|}{ Histological Grade } \\
\hline I & $43(20.5)$ & & \\
\hline II & $123(58.6)$ & & \\
\hline III & $44(21)$ & & \\
\hline NA & 21 & & \\
\hline \multicolumn{4}{|l|}{ Nuclear Grade } \\
\hline I & $35(26.1)$ & & \\
\hline II & $75(56)$ & & \\
\hline III & $24(17.9)$ & & \\
\hline NA & 97 & & \\
\hline \multicolumn{4}{|c|}{ Lymph node involvement } \\
\hline Yes & $137(64)$ & & \\
\hline No & $77(36)$ & & \\
\hline NA & 17 & & \\
\hline \multicolumn{4}{|l|}{ Vascular Invasion } \\
\hline Yes & $122(65.6)$ & & \\
\hline No & $64(34.4)$ & & \\
\hline NA & 45 & & \\
\hline \multicolumn{4}{|l|}{ ER } \\
\hline Positive & $135(58.4)$ & & \\
\hline Negative & $96(41.6)$ & & \\
\hline \multicolumn{4}{|l|}{ PR } \\
\hline Positive & $128(55.4)$ & & \\
\hline Negative & $103(44.6)$ & & \\
\hline \multicolumn{4}{|l|}{ HER2 } \\
\hline Positive & $138(59.7)$ & & \\
\hline Negative & $93(40.3)$ & & \\
\hline \multicolumn{4}{|l|}{ P53 } \\
\hline Positive & $104(45)$ & & \\
\hline Negative & $127(55)$ & & \\
\hline \multicolumn{4}{|l|}{ Ki67 } \\
\hline$<20 \%$ & $126(54.5)$ & & \\
\hline$\geq 20 \%$ & $105(45.5)$ & & \\
\hline \multicolumn{4}{|l|}{ Subtypes } \\
\hline Luminal A & $77(33.3)$ & & \\
\hline Luminal B & $71(30.7)$ & & \\
\hline HER2 disease & $22(6.6)$ & & \\
\hline $\begin{array}{l}\text { Triple, } \\
\text { negative/basal-like }\end{array}$ & $61(26.4)$ & & \\
\hline
\end{tabular}

$\mathrm{SD}$, standard deviation; $\mathrm{ER}$, estrogen receptor; $\mathrm{PR}$, progesterone receptor; HER2, the human epidermal growth factor. 
Expression of 53 in Breast Cancer in Kurdish Women in West Iran: a Reverse Correlation with Lymph Node Metastasis

Table 2. The correlation between the expression of $\mathrm{p53}$ with other factors in breast cancer patients

\begin{tabular}{|c|c|c|c|}
\hline \multirow[t]{2}{*}{ Variables } & \multicolumn{2}{|c|}{ P53-positive P53-negative } & \multirow[t]{2}{*}{ P-value* } \\
\hline & $\mathrm{n}$ & $\mathrm{n}$ & \\
\hline \multicolumn{3}{|c|}{ Age group(year), n=231 } & 0.047 \\
\hline$\leq 50$ & 61 & 89 & \\
\hline$>50$ & 43 & 38 & \\
\hline \multicolumn{3}{|c|}{ Tumor Size $(\mathrm{cm}), n=121$} & 0.08 \\
\hline$<2$ & 18 & 13 & \\
\hline$\geq 2$ & 81 & 109 & \\
\hline \multicolumn{3}{|c|}{ Histological Grade, $n=210$} & 0.000 \\
\hline $\mathrm{I}$ & 25 & 18 & \\
\hline II & 32 & 91 & \\
\hline III & 35 & 9 & \\
\hline \multicolumn{3}{|c|}{ Nuclear Grade, $n=134$} & 0.000 \\
\hline I & 21 & 14 & \\
\hline II & 15 & 60 & \\
\hline III & 23 & 1 & \\
\hline \multicolumn{3}{|c|}{ Lymph node involvement, $\mathrm{n}=214$} & 0.000 \\
\hline Yes & 48 & 89 & \\
\hline No & 50 & 27 & \\
\hline \multicolumn{3}{|c|}{ Vascular Invasion, $\mathrm{n}=186$} & 0.001 \\
\hline Yes & 45 & 77 & \\
\hline No & 39 & 25 & \\
\hline \multicolumn{3}{|l|}{$E R, n=231$} & 0.000 \\
\hline Positive & 45 & 90 & \\
\hline Negative & 59 & 37 & \\
\hline \multicolumn{3}{|l|}{$P R, n=231$} & 0.000 \\
\hline Positive & 43 & 85 & \\
\hline Negative & 61 & 42 & \\
\hline \multicolumn{3}{|l|}{ HER $2, n=231$} & 0.001 \\
\hline Positive & 74 & 64 & \\
\hline Negative & 30 & 63 & \\
\hline \multicolumn{3}{|l|}{$\mathrm{Ki67}, \mathrm{n}=231$} & 0.001 \\
\hline$<20 \%$ & 45 & 81 & \\
\hline$\geq 20 \%$ & 59 & 46 & \\
\hline
\end{tabular}

P-value derived from chi-square test for trend; SD, standard deviation; ER, estrogen receptor; PR, progesterone receptor; HER2, the human epidermal growth factor

lymph node metastasis, vascular invasion, ER, PR, HER2 and Ki67 $(\mathrm{P}<0.05)$, but there was no for tumor size $(\mathrm{P}>0.05)$. More patients with p53-positive have age $\leq 50$ years, higher grade, ER-negative, PR-negative, HER2-positive and Ki67 $\geq 20 \%$, but there was inverse correlation between lymph node metastasis and vascular invasion with the expression of p53 that there were less lymph node metastasis and vascular invasion in patients with p53-positive.

The Table 1 shows percent of subtypes of BC in all patients and the Figure 1 shows the correlation between subtypes of $\mathrm{BC}$ with the expression of $\mathrm{p} 53$. In patients with $\mathrm{TN} /$ basal-like, p53-positive is more than other subtypes and for luminal B, p53-negative is more than other groups $(\mathrm{P}=0.000)$.

Binary logistic regression analysis between the variables with the expression of p53 has been shown in Table 3. There was inverse significant correlation between lymph node metastasis $(\mathrm{P}=0.008$, OR 0.120 and 95\%CI 0.025-0.574), ER status $(\mathrm{P}=0.006$, OR 0.080 , 95\%CI 0.014-0.477) and a direct correlation between HER2 ( $\mathrm{P}=005$, OR 3.047, 95\%CI 1.407-6.599) with the expression of $\mathrm{p} 53$.
Table 3. Binary logistic regression analysis between the variables with the expression of p53

\begin{tabular}{|c|c|c|c|}
\hline Variables & P-value & OR & $95 \% \mathrm{CI}$ \\
\hline $\begin{array}{l}\text { Age group (year) } \\
\text { ( } \leq 50 \mathrm{vs} .>50)\end{array}$ & 0.068 & 0.223 & $0.044-1.120$ \\
\hline $\begin{array}{l}\text { Histological Grade } \\
\text { (grades I and II vs. III) }\end{array}$ & 0.3 & 0.582 & $0.209-1.621$ \\
\hline $\begin{array}{l}\text { Nuclear Grade } \\
\text { (grades I and II vs. III) }\end{array}$ & 0.153 & 2.285 & $0.735-7.104$ \\
\hline $\begin{array}{l}\text { Lymph node involvement } \\
\text { (positive vs. negative) }\end{array}$ & 0.008 & 0.12 & $0.025-0.574$ \\
\hline $\begin{array}{l}\text { Vascular Invasion } \\
\text { (positive vs. negative) }\end{array}$ & 0.503 & 0.54 & $0.089-3.280$ \\
\hline ER(positive & 0.006 & 0.08 & $0.014-0.477$ \\
\hline PR(positive vs. negative) & 0.535 & 1.71 & $0.314-9.331$ \\
\hline HER2(positive vs. negative) & 0.005 & 3.047 & $1.407-6.599$ \\
\hline Ki67 (<20\% vs. $\geq 20 \%)$ & 0.432 & 0.545 & $0.120-2.476$ \\
\hline
\end{tabular}

A binary logistic regression model was selected using Akaike Information Criteria (AIC) in stepwise selection. Odds ratios are adjusted for all of the factors listed in the table. Abbreviations: SD, standard deviation; ER, estrogen receptor; PR, progesterone receptor; HER2, the human epidermal growth factor; OR, odds ratio.

\section{Discussion}

The p53 tumor suppressor gene product participated in G1 cell cycle arrest or cell death. Loss of function was associated with poor outcome in patients with breast carcinoma (Arun et al., 2003).

A study suggested that p53 expression in axillary metastatic lymph node specimens is correlated with p53 expression in the primary tumor tissue specimens. The prognostic and predictive value of p53 expression in axillary lymph node metastasis in patients with breast carcinoma needs to be further evaluated in larger trials with longer follow-up (Arun et al., 2003). A number of studies reported that the expression of p53 had direct correlation with tumor size (Osanai et al., 2005), histological grade (Qing et al., 2014; Osanai et al., 2005; Sirvent et al., 1995; Bertheau et al., 1998), nuclear grade (Jasar et al., 2015), lymph-vascular invasion (Osanai et al., 2005), the proliferation index Ki67 (Jasar et al., 2015) and ER status (Osanai et al., 2005; Li et al., 2015), but other studies showed that the expression of p53 had inverse correlation with histological grade(el-A Helal et al., 2000), lymph-vascular invasion (Jasar et al., 2015), non-sentinel lymph node invasion (Vernet et al., 2015) and estrogen (Sirvent et al., 1995) and progesterone receptors (Sirvent et al., 1995; Bertheau et al., 1998). Also, a number of studies reported that there was no significant correlation between the expression of p53 and age (Qing et al., 2014), clinical stage (Qing et al., 2014), or lymph node metastasis (Sirvent et al., 1995; Sjostrom-Mattson et al., 2009; Qing et al., 2014) in the BC. In 50 patients with TNBC and invasive ductal carcinoma, there was a direct correlation between Ki67 and p53 in TNBC patients that for better conclusion it needs more studies (Payandeh et al., 2015c). In our study, there was significant correlation between the expression of p53 with age group, histological grade, nuclear grade, lymph node metastasis, vascular invasion, ER, PR, HER2 and Ki67 index, but there was no for tumor size that binary logistic regression analysis showed that 
there was inverse significant correlation between lymph node metastasis and a direct correlation between HER2 and ER status with expression of p53. P53 expression was associated with prognosis in women of 36-50 years (Bertheau et al., 1998) that in our study, more patients with p53-positive have age $\leq 50$ years.

Frequency of subtypes for BC is: (Voduc et al., 2010) Luminal type A (40\%), Luminal type B (20\%), TN/basallike (15-20\%) and HER2 disease (10-15\%). In the study of several researcher (Carey et al., 2006), out of 657 analyzed cases of BC, $26 \%$ were TN, and the great series of Rakha and colleagues (Rakha et al., 2007) from 1944 patients TN were $16.3 \%$. Of all the BC tissue analyzed, $43.79 \%$ was positive for p53 (Sirvent et al., 1995). The expression of p53 and EGFR as well as their correlation in the different subtypes were determined (Wang et al., 2015). High expression of p53 was observed in TNBC, which may synergistically contribute to the pathogenesis of TNBC (Li et al., 2015). A study (Wang et al., 2015), showed that among the four subtypes, luminal B was the most common type that the expression of p53 was higher in luminal B, HER 2 disease, and TNBC. In a other research was reported that the highest level p53 was found in Her2 disease and TN/basal-like tumor subtypes (Shapochka et al., 2012). In our study, luminal A, luminal B, HER2 disease and TN were $33.3 \%, 30.7 \%, 6.6 \%$ and $26.4 \%$, respectively, that luminal A had the most percent and this result was similar to other studies, but luminal B was the lowest and was contrasting with the other results. Also, in this study, there was a significant correlation between p53 expression with subtypes of $\mathrm{BC}$ and $\mathrm{p} 53$ expression was the most for TN subtype such as other results, but was less in other subtypes, unlike the results of other studies.

In a number of studies, expression of p53 had inverse correlation with lymph node metastasis and ER status and also a direct correlation with HER2 status. Further studies in other centers are needed to confirm p53 expression as a strong predictor of lymph node metastasis and ER status negativity. Also, p53-positive is more in TNBC compared to other subtypes.

\section{References}

Aeinfar M, Najafi S, Payandeh M, Sadeghi M, Sadeghi E (2015). Clinicopathology figures of breast cancer women with brain metastasis and invasive ductal carcinoma. Am J Cancer Prev, 3, 68-71.

Arun B, Kilic G, Yen C, et al (2003). Correlation of Bcl-2 and p53 expression in primary breast tumors and corresponding metastatic lymph nodes. Cancer, 98, 2554-9.

Aylon Y, Oren M (2011). New plays in the p53 theater. Curr Opin Genet Dev, 21, 86-92.

Bertheau P, Steinberg SM, Merino MJ (1998). C-erbB-2, $\mathrm{p} 53$, and $\mathrm{nm} 23$ gene product expression in breast cancer in young women: immunohistochemical analysis and clinicopathologic correlation. Hum Pathol, 29, 323-9.

Carey LA, Perou CM, Livasy CA, et al (2006). Race, breast cancer subtypes, and survival in the Carolina Breast cancer Study. JAMA, 295, 2492-502.

De Azambuja E, Cardoso F, De Castro G, et al (2007). Ki67 as prognostic marker in early breast cancer: a meta-analysis of pub-lished studies involving 12.155 patients. Br J Cancer, 96, 1504-13.
el-AHelal T, Khalifa A, Kamel AS (2000). Immunohistochemical expression of $\mathrm{p} 53$ and c-erbB2 proteins in breast cancer in Egypt. Anticancer Res, 20, 2145-50.

Howard EM, Lau SK, Lyles RH, et al (2004). Correlation and expression of p53, HER-2, vascular endothelial growth factor (VEGF), and e-cadherin in a high-risk breast-cancer population. Int J Clin Oncol, 9, 154-60.

Jasar Dz, Smichkoska S, Kubelka K, Filipovski V, Petrushevska $\mathrm{G}$ (2015). Expression of p53 protein product in triple negative breast cancers and relation with clinical and histopathological parameters. Prilozi, 36, 69-79.

Lacroix M, Toillon RA, Leclercq G (2006). p53 and breast cancer, an update. Endocr Relat Cancer, 13, 293-325.

Li X, Wang Q, Fu L, Liu M, Yu X (2015). Expression of PTEN, p53 and EGFR in the molecular subtypes of breast carcinoma and the correlation among them. Zhong Nan Da Xue Xue Bao Yi Xue Ban, 40, 973-8 (in Chinese).

Osanai T, Takagi Y, Toriya Y, et al (2005). Inverse correlation between the expression of O6-methylguanine-DNA methyl transferase (MGMT) and p53 in breast cancer. Jpn J Clin Oncol, 35, 121-5.

Payandeh M, Malayeri R, Sadeghi M, Sadeghi E, Gholami, F (2015c). Expression of p53 and Ki67 in the patients with triple negative breast cancer and invasive ductal carcinoma. Am J Cancer Prev, 3, 58-61.

Payandeh M, Sadeghi M, Sadeghi E, Aeinfar M (2015a). Clinicopathology figures and long-term effects of tamoxifen plus radiation on survival of women with invasive ductal carcinoma and triple negative breast cancer. Asian Pac J Cancer Prev, 16, 4863-7.

Payandeh M, Sadeghi M, Sadeghi E (2015b). Differences in prognostic factors between early and late recurrence breast cancers. Asian Pac J Cancer Prev, 16, 6575-9.

Pharoah PD, Day NE, Caldas C (1999). Somatic mutations in the 553 gene and prognosis in breast cancer: a meta-analysis. Br J Cancer, 80, 1968-73.

Qing Z, Zou W, Luo J, Wen Q, Fan S (2014). [p53 protein expression in HER2-negative breast invasive ductal carcinoma]. Zhong Nan Da Xue Xue Bao Yi Xue Ban, 39, 1016-22.

Rakha EA, El-Sayed ME, Green AR, et al (2007). Prognostic markers in triple negative breast cancer. Cancer, 109, 25-32.

Shapochka DO, Zaletok SP, Gnidyuk MI (2012). Relationship between NF- $x$ B, ER, PR, Her2/neu, Ki67, p53 expression in human breast cancer. Exp Oncol, 34, 358-63.

Sirvent JJ, Salvado MT, Santafe M, et al (1995). p53 in breast cancer. Its relation to histological grade, lymph-node status, hormone receptors, cell-proliferation fraction (ki-67) and c-erbB-2. Immunohistochemical study of 153 cases. Histol Histopathol, 10, 531-9.

Sjostrom-Mattson J, Von Boguslawski K, Bengtsson NO, et al (2009). The expression of p53, bcl-2, bax, fas and fasL in the primary tumour and lymph node metastases of breast cancer. Acta Oncol, 48, 1137-43.

Temmim L, Baker H, Sinowatz F (2001). Immunohistochemical detection of $\mathrm{p} 53$ protein expression in breast cancer in young Kuwaiti women. Anticancer Res, 21, 743-8.

Vernet-Tomás M, Baños N, Sabadell D, et al (2015). p53 expression in breast cancer predicts tumors with low probability of non-sentinel nodes infiltration. $J$ Obstet Gynaecol Res, 41, 1115-21.

Voduc KD, Cheang MC, Tyldesley S, et al (2010). Breast cancer subtypes and the risk of local and regional relapse. J Clin Oncol, 28, 1684-91.

Wang XZ, Liu Q, Sun JJ, et al (2015). Correlation between p53 and epidermal growth factor receptor expression in breast cancer classification. Genet Mol Res, 14, 4282-90. 